\title{
Renal Tumor Causing Haematuria and Sepsis
}

\author{
Attila SZENDRŐI, ${ }^{1}$ András RUSZ, ${ }^{1}$ Eszter SZÉKELY, ${ }^{2}$ Péter RIESZ, ${ }^{1}$ Zsolt KELEMEN ${ }^{1}$ \\ ${ }^{1}$ Department of Urology, ${ }^{2} 2^{\text {nd }}$ Department of Pathology, Semmelweis University, Budapest
}

\begin{abstract}
A 28 year old female patient developed hematuria in the 32 th week of her pregnancy. She was given antibiotic treatment, since a urinary tract infection was suspected. After delivery symptoms of acute pyelonephritis, then sepsis developed, and conservative therapy had no effect. Ultrasound examina-
\end{abstract}

tion showed unusual renal destruction, so nephrectomy was performed. Surgical intervention revealed the presence of an advanced tumor of the kidney, while histological examination confirmed a Bellini duct carcinoma of the kidney. (Pathology Oncology Research Vol 9, No 4, 246-248)

Keywords: haematuria, pregnancy, kidney tumor, Bellini duct cancer

\section{Introduction}

The Heidelberg classification (1997) identifies 4 renal cell cancer groups on the basis of histological features and genetic alterations: common, papillary, chromophobe and collecting duct renal cell cancer. ${ }^{5}$ Bellini duct cancer has its origin in the epithelium of the collecting duct, and it amounts to just $0.4-2.6 \%$ of the malignacies of the kidney. ${ }^{1}$ It is much more malignant than the other types of renal cell cancer both in local extension and in lymphogeneous, haematogeneous spread. It is often already metastatized at the time of diagnosis, and its prognosis is rather poor. ${ }^{6}$ The tumor gives lymphogeneous metastases to the paraaorical and paracaval lymphnodes, while haematogeneously the liver, lung and bone are the predilection sites of the metastases. The primary tumor is symptomless, the first symptoms are bone metastases or loss of weight of an advanced disease. ${ }^{9}$ The most useful devices in the diagnostic procedure of renal tumors are ultrasound and computed tomography scan., ${ }^{2,9}$

In young adults (under 40) the therapy, prognosis and survival are the same as in elderly patients. ${ }^{4}$

\section{Case report}

Is it acute pyelonephritis?

A 28 year old woman had an uneventful pregnancy till the 32th week, when microscopic haematuria was found by her gynaecologist. Ultrasound examination revealed a

Received: Oct 10, 2003; accepted: Nov 10, 2003

Correspondence: Attila SZENDRŐI MD, Department of Urology, Semmelweis University, H-1078 Budapest, Üllői út 78/b, Tel: (36-1)210-03-30, Fax: (36-1)-210-03-05, e-mail: atsszendroi@freemail.hu
$26 \mathrm{~mm}$ cyst on the lower pole of the left kidney. Since non complicated acute pyelonephritis was suspected, she was given a course of oral antibiotics. Thereafter she became symptom free without any complaints. She gave birth to a healthy child in the $40^{\text {th }}$ week of pregnancy. During the second week of puerperum, however, she visited our Department due to the development of left-sided renal pain accompanied by fever $\left(39.2^{\circ} \mathrm{C}\right)$ and ceased pain lactation.

\section{Is it a renal abscess?}

Ultrasound showed medium degree dilatation of the left renal pelvis, with hypoechogeneous, inhomogeneous tumescence on the lower part. A $6 \mathrm{~mm}$ cyst was detectable on the right kidney. The patient's condition became worse despite of parenteral administration of antibiotics, and septic fever developed. The CRP (C reactive protein) value was $125 \mathrm{mg} / \mathrm{l}$, the haemoglobin level was $82 \mathrm{~g} / \mathrm{l}$, the erythrocyte sedimentation rate (ESR) was $125 \mathrm{~mm} / \mathrm{h}$ and leukocyturia was found.

Given the acute progression and the unusual clinical behaviour surgery was decided on, since acute computed tomography was considered to have no therapeutical effect. The left kidney was removed by lumbar surgical approach, which proved difficult due to the scarred, firm retroperitoneum. Enlarged hilar lymph nodes were also found. The removed kidney was enlarged, measuring $135 \times 85 \times 55 \mathrm{~mm}$ and weighing 505 grams, and was found incorporated into an inhomogeneous, solid tumor which involved the capsula adiposa and the renal pelvis. (Figure 1.) 


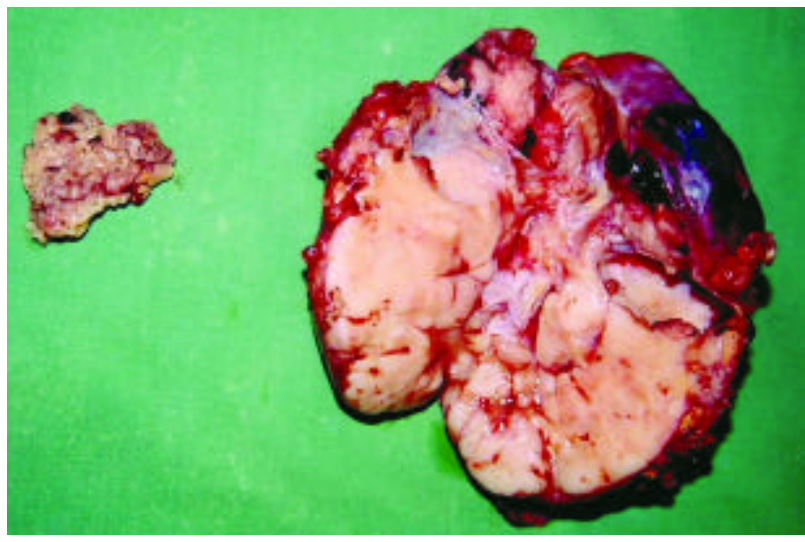

Figure 1. Macroscopic picture of the removed left kidney

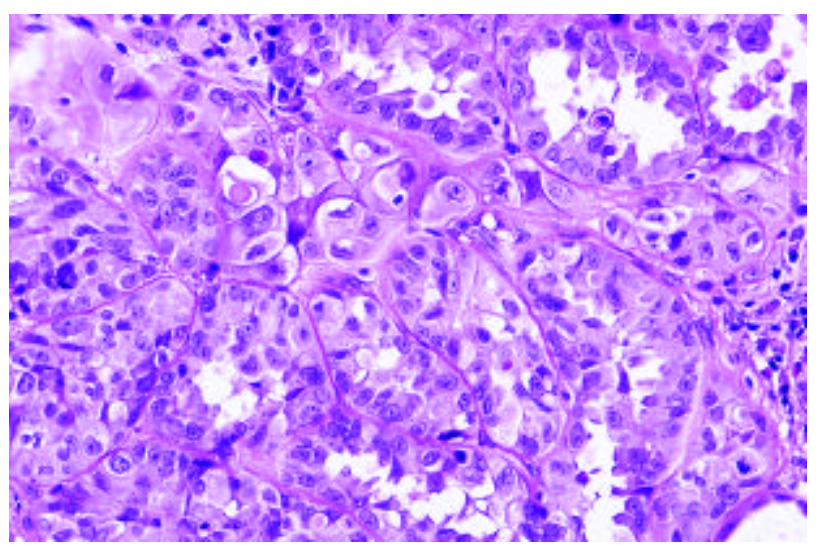

Figure 2. Histology of the tumor (HE)

\section{Is it renal cell cancer?}

The postoperative period after nephrectomy was uneventful, the patient had no fever, symptoms or complaints. The tumor was considered an anaplastic transitional cell renal cancer by the hematoxylin-eosin picture, (T3G4) (Figure 2), and additional immunohistochemical reactions. (Figure 3) No tumor cells were found in the removed enlarged parahilar lymph nodes. Computed tomography $(\mathrm{CT})$ performed on the $18^{\text {th }}$ postoperative day revealed a $3 \times 4 \mathrm{~cm}$ sized tumescense, in the place of the removed kidney at the level of the second thoracic vertebra. The tumescence was probably equal with the enlarged lymph nodes found intraoperatively. The $8 \mathrm{~mm}$ cyst on the right kidney found previously by ultrasound seemed to be a potential contralateral renal tumor. Postoperative bone scan and chest $\mathrm{X}$ ray were performed, giving negative results. Based on the obtained data the patient was sent to the National Institute of Oncology for chemotherapy, where histological rewiew of the tumor with additional immunohistochemical reactions were performed, five months after the nephrectomy. The final diagnosis was collecting duct tumor (Bellini) based on the haematoxylin eosin picture, and the clinical behaviour in spite of the results of additional immunohistochemical examinations.

\section{Is it postinjection abscess?}

The patient returned to our department one month after the operation and before commencing chemotherapy, due to the painful tumescence of the right gluteal region. Because the possibility of postinjection abscess emerged, surgical consultation was required. The surgeon precluded the possibility of an abscess by the ultrasound picture. Sixteen days after the bone scan, MR examination was performed, extended to the gluteal region as well. The examination revealed a tumor expanding to the right sacrum massa lateralis and musculus pyriformis. It also confirmed the presence of a retroperitoneal mass seen previously on the CT scan in the bed of the removed kidney, and considered the $8 \mathrm{~mm}$ tumescence of the right kidney to be a cyst. The patient was referred to an orthopaedic surgeon due to the gluteal tumor. A biopsy was performed, the histological result of which was metastasis of an anaplastic tumor. A thorough examination of the bone scan revealed minimal positivity at this region, but it seemed to be a sacroileitis rather than such a large tumor metastasis. Considering the extensive retroperitoneal mass, the orthopaedist did not advise hemipelvectomy.

The patient was referred to the National Institute of Traumatology with pathologic spine fracture. A CT scan revealed lytic metastases of the thoracic IX, lumbar III vertebrae. Surgical fixation of the fracture and local radiotherapy were performed, following which the patient received chemotherapy at the National Institute of Oncology.

\section{Discussion}

Despite the negative family history this tumor is similar to hereditary, familial cancers because it appears in young age (28 years) and its progression is rapid. That is why it

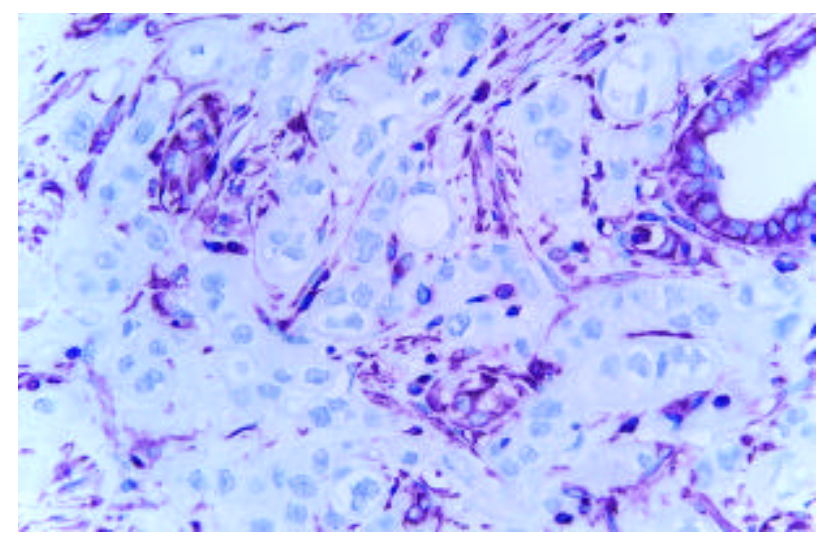

Figure 3. Immunohistochemical reaction (vimentin) 
is important to make genetic examinations and also follow up of the child closely for a long time.

It is obligatory to make a renal ultrasound examination when a pregnant patient has haematuria, fever, renal colic, flank tenderness; and it is also important to consider a renal tumor even if it is a rarity at this age. The value of ultrasound examination is limited, if it is such a solid infiltrating renal mass; in our case we were only able to verify the tumor unambighously during the operation. Computed tomography scan and urography should be avoided because of the harmful effect of $\mathrm{X}$ ray during pregnancy.

The bone scan did not unambignously indicate spinal metastases. The reason may be the rapid progression (3 weeks between the bone scan and the MRI), or because some metastases (for example myeloma multiplex) cause less positivity of the bone scan. We were unable to find any reference in the literature to the intensity of bone metastases of anaplastic or collecting duct cancer in the bone scan. In our case there was no point in undertaking further surgical intervention (resection of the retroperitoneal or bone metastasis), as these interventions have no effect on survival or on quality of life. , $^{3,6}$

Immunohistochemical examinations are very important for the diagnosis procedure of anaplastic tumors, because haematoxylin-eosin slides alone are not enough to establish the origin of the tumor. The result of immunohistochemical examinations can be misleading in certain cases, including our case, since the first histological result suggested anaplastic transitional cell cancer because of the morphological structure of the haematoxylin-eosin slides and the vimentin negativity. This immunohistochemical reaction is generally positive in Bellini duct tumor and negative in transitional cell. Further immunohistochemical examinations carried out 5 months after nephrectomy at pathological review of the tumor made us change our opinion as they indicate Bellini duct cancer despite vimentin negativity. Because the oncological therapy is based on the histological results, thorough histological and immunohistochemical examinations are very important. Electron microscopical or tumor genetic examinations should be carried out. Unfortunately in our case this was a purely academic question, because we have no histologically specific therapy which could have an effect on the survival or the quality of life in such advanced case of either Bellini duct tumor, or transitional cell cancer. ${ }^{3,6,7,8}$

\section{References}

1. Antonelli A, Portesi E, Cozzoli A, et al: The collecting duct carcinoma of the kidney: a cytogenetical study. Eur Urol 43:680685, 2003

2. Belldegrun A, deKernion JB: Renal tumors In: Campbell's Urology, $7^{\text {th }}$ ed. Edited by PC Walsh, AB Retik, TA Stamey and ED Vaughan. Philadelphia: WB Saunders Co., vol.3, Chapt 76, pp. 2283-2327, 1998

3. Cheville JC, Lohse CM, Zincke H, et al: Comparisons of outcome and prognostic features among histologic subtypes of renal cell carcinoma Am J Surg Pathol 27:612-24, 2003

4. El Fettouh HIA, Cherullo E, El-Jack M, et al: Sporadic renal cell carcinoma in young adults: presentation, treatment and outcome. Urology 60: 806-810, 2002

5. Kovacs G, Akhtar M, Beckwith BJ, et al: The Heidelberg classification of renal cell tumors. J Path 183:131, 1997

6. Mejean A, Roupret M, Larousserie F,et al: Is there a place for radical nephrectomy in the presence of metastatic collecting duct (Bellini) carcinoma? J Urol 169:1287-90, 2003

7. Mickisch GHJ: Rational selection of a control arm for randomised trials in metastatic renal cell carcinoma Eur Urol 43:670-679, 2003

8. Poel van der H.G, Roukema JA, Horenblas S, et al: Metastectomy in renal cell carcinoma: a multicenter retrospective analysis. Eur Urol 35:197-203, 1999

9. Romics I, Goepel M: A here és vesedaganatok diagnosztikája és terápiája. Akadémiai Kiadó, 1998 